SFB

Market premia for renewables in Germany: The effect on electricity prices

Manuel Frondel, Matthias Kaeding,

Stephan Sommer

Nr. $13 / 2020$

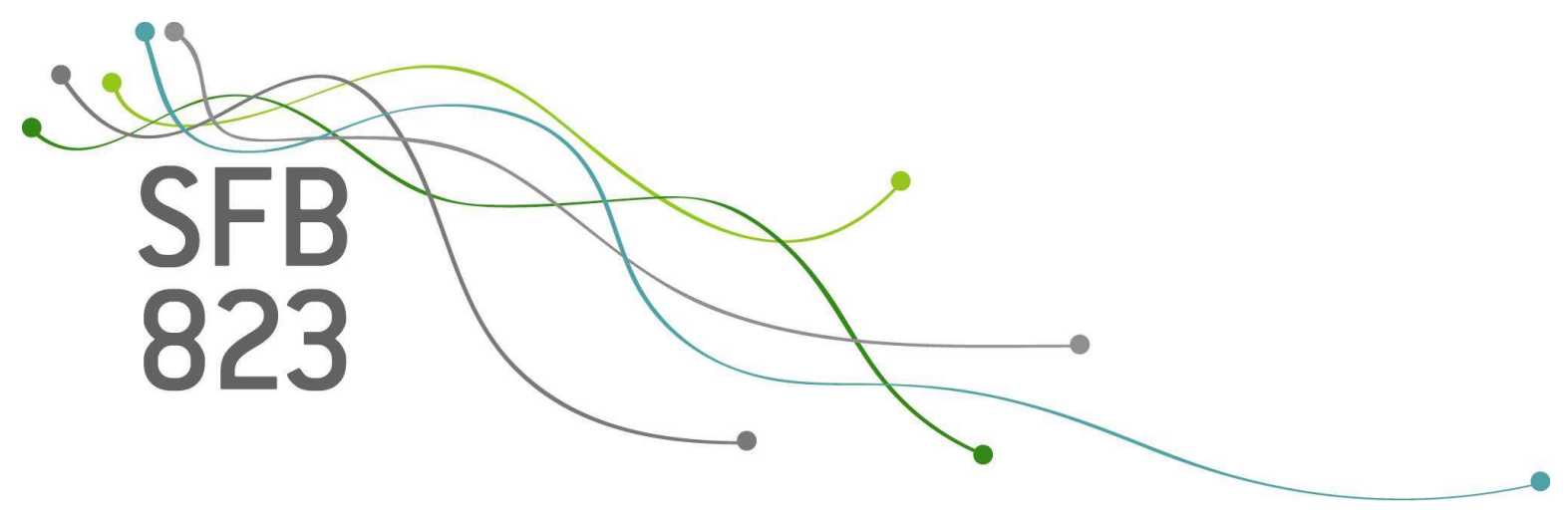





\title{
Market Premia for Renewables in Germany: The Effect on Electricity Prices
}

\author{
Manuel Frondel, Matthias Kaeding; Stephan Sommer ${ }^{\ddagger}$
}

April 28, 2020

\begin{abstract}
Due to the growing share of "green" electricity generated by renewable energy technologies, the frequency of negative price spikes has substantially increased in Germany. To reduce such events, in 2012, a market premium scheme (MPS) was introduced as an alternative to feed-in tariffs for the promotion of green electricity. Drawing on hourly day-ahead spot prices for the time period spanning 2009 to 2016 and employing a nonparametric modeling strategy called Bayesian Additive Regression Trees, this paper empirically evaluates the efficacy of Germany's MPS. Via counterfactual analyses, we demonstrate that the introduction of the MPS decreased the number of hours with negative prices by some $70 \%$.
\end{abstract}

JEL Codes: C11, H10, Q41.

Keywords: Negative electricity prices, Merit order effect, Bayesian Additive Regression Trees.

Acknowledgements: We thank Johanna Meier and Christian Stehr for excellent research assistance and are highly grateful for valuable comments and suggestions by Philipp Breidenbach, Fabian Dehos, Kathrin Kaestner, Gerhard Kussel, Mike Price, Sandra Schaffner, and Colin Vance. We gratefully acknowledge financial support by the Collaborative Research Center "Statistical Modeling of Nonlinear Dynamic Processes" (SFB 823) of the German Research Foundation (DFG), within Project A3, "Dynamic Technology Modeling" and by the Federal Ministry of Education and Research (BMBF) under grant 01LA1809C (Project DIPOL) and grant 01LA1823A (Project Eval-Map II) within the funding measure "Economics of Climate Change".

*RWI Leibniz Institute for Economic Research and Ruhr-University Bochum, frondel@rwi-essen.de

${ }^{\dagger}$ RWI Leibniz Institute for Economic Research, kaeding@rwi-essen.de

${ }^{\ddagger}$ RWI Leibniz Institute for Economic Research, sommer@rwi-essen.de 


\section{Introduction}

Almost all over the world, policy-makers foster for the deployment of renewable energy technologies, such as solar and wind power, as a means to reduce carbon emissions. The European Union (EU), for instance, aims at raising the share of "green" electricity, produced by renewable energy technologies, in electricity consumption from about $29 \%$ in 2015 to $56 \%$ by 2030 (Agora, 2019). To achieve this target, the majority of Member States has established promotion schemes for enewable energy sources (RES) that are based on subsidies (IEA and IRENA, 2018).

In Germany, for example, since the beginning of the new millennium, green electricity has been promoted via technology-specific feed-in tariffs (FITs) that guarantee fixed payments per kilowatthour (kWh) to the plant operators for up to 21 years. Moreover, grid operators are obliged to give priority dispatch to RES (Andor et al., 2017). In the aftermath of the introduction of the feed-in tariff system, Germany has been very successful

in increasing RES capacities, yet their massive increase has come at high cost: Currently, the annual promotion costs amount to more than 25 billion euros, equaling about $1 \%$ of the German GDP (Andor et al., 2018).

In addition to the substantial cost due to the unconditonal payment of fixed tariffs irrespective of demand levels, the steadily growing amount of green electricity has further adverse economic effects: it tends to increase both grid balancing costs and the frequency of negative prices (Weber, 2010; Nicolosi, 2010). In fact, while RES plants are not obliged to contribute to grid stability, abundant green electricity production may lead to negative prices when a high electricity supply coincides with a low demand, thereby inducing welfare losses (Andor et al., 2010).

Gerster (2016), for instance, demonstrates that the growing feed-in of green electricity raises the probability of negative price spikes and thus threatens the financial viability of conventional plants. Negative prices primarily arise because conventional power plants face substantial ramp-up costs (Gerster, 2016) and, hence, are most often not shut down 
despite negative revenues due to negative prices. Not least, numerous studies argue that there is a negative link between green electricity generation and the wholesale price, commonly referred to as the merit-order effect (Cludius et al., 2014; de Lagarde and Lantz, 2018; Paschen, 2016; Praktiknjo and Erdmann, 2016; Würzburg et al., 2013).

To avoid such adverse effects and to align the production of green electricity with market signals, many countries have implemented market premium schemes that pay operators of renewable plants a variable bonus on top of the wholesale electricity price, rather than guaranteeing fixed feed-in-tariffs (RES, 2018). Germany, for example, introduced such a market premium scheme (MPS) in January 2012 and revised it in August 2014.

Using hourly day-ahead spot prices for the time period spanning January 2009 to December 2016, this paper empirically evaluates the efficacy of the German MPS, particularly with respect to reducing the frequency of negative price spikes. To this end, we employ a nonparametric modeling strategy called Bayesian Additive Regression Trees (BART), which is highly appropriate for identifying nonlinear interactions between covariates (Hill, 2011) and for predicting those electricity prices that would have emerged in the counterfactual scenario without the MPS. Our results indicate that the BART method is very successful in replicating past electricity prices, as we are able to replicate those roughly 470 hours in which negative prices occurred within the sample period of 2009 to 2016.

Moreover, our results suggest that the introduction of the MPS led to less hours with negative prices, particularly in the morning, and less positive price peaks relative to the counterfactual situation of an absent MPS. By comparison with this counterfactual, we demonstrate that negative electricity prices were avoided by some $70 \%$, in more than 560 hours. Based on these empirical results, we conclude that the MPS turned out to be effective in increasing the market integration of renewable energy technologies and, hence, in reducing the costs of their promotion. 
The subsequent sections describe Germany's electricity market and its MPS, as well as the data base underlying our research. Section 4 briefly introduces the BART modeling method, while Section 5 presents our empirical results. The last section summarizes and concludes.

\section{Germany's Market Premium for RES}

Germany stipulated ambitious targets for the expansion of RES, aiming at increasing the share of RES-based electricity in consumption to $35 \%$ by 2020 and to $80 \%$ by 2050 . As more than $35 \%$ of electricity consumption was covered by RES technologies in 2019, compared to less than 7\% in 2000 (BMWi, 2017), Germany has already reached its 2020 target. Clearly, the key driver of this rapid expansion is the Renewable Energy Sources Act (Erneuerbare-Energien-Gesetz, EEG), which came into force in 2000. Its key characteristic is a set of technology-specific FITs that are granted for up to 21 years in an intertemporally fixed amount. While exceeding the average generation cost of conventional electricity, in many cases substantially, these technology-specific tariffs are paid for each kWh fed into the grid irrespective of the level of demand for electricity. In addition, electricity based on RES enjoys preferential access to the grid. Both features, FITs and priority of green over conventional electricity, were established to shield plant operators from adverse market signals (Andor and Voss, 2016).

In terms of RES capacity expansion, Germany's FIT system proved highly successful: Between 2000 and 2016, RES capacities increased ten-fold to reach 104 Gigawatt (GW), thereby exceeding the capacity of conventional power plants for the first time (BMWi, 2017). Above all, photovoltaic (PV) capacities skyrocketed, most notably in the boom

years 2010 to 2012: In each of these years, almost 8 GW were newly installed, with the sum of PV capacities installed in this period being equivalent to almost $60 \%$ of the total PV capacity in 2016 (Table 1). With an increment of about 4 GW in 2016, prior to Germany's 
introduction of auctioning systems for the installation of new renewable energy plants in 2017, onshore wind has experienced a strong push as well.

Table 1: Electricity Generation Capacity (in Megawatt) in Germany Prior to the Introduction of a Tendering System in 2017

\begin{tabular}{ccccccc}
\hline & $\begin{array}{c}\text { Hydro, } \\
\text { Bio, Geo }\end{array}$ & $\begin{array}{c}\text { Wind } \\
\text { Onshore }\end{array}$ & $\begin{array}{c}\text { Wind } \\
\text { Offshore }\end{array}$ & $\begin{array}{c}\text { Photo- } \\
\text { voltaic }\end{array}$ & $\begin{array}{c}\text { Total } \\
\text { Renewables }\end{array}$ & $\begin{array}{c}\text { Total } \\
\text { Conventional }\end{array}$ \\
\hline 2000 & 5,534 & 6,097 & 0 & 114 & 11,745 & 107,500 \\
2001 & 5,658 & 8,738 & 0 & 176 & 14,572 & 106,800 \\
2002 & 5,967 & 11,976 & 0 & 296 & 18,239 & 100,900 \\
2003 & 6,381 & 14,381 & 0 & 435 & 21,197 & 99,400 \\
2004 & 6,873 & 16,419 & 0 & 1,105 & 24,397 & 100,900 \\
2005 & 7,562 & 18,248 & 0 & 2,056 & 27,866 & 98,900 \\
2006 & 8,203 & 20,474 & 0 & 2,899 & 31,576 & 98,400 \\
2007 & 8,532 & 22,116 & 0 & 4,170 & 34,818 & 99,800 \\
2008 & 8,848 & 22,794 & 0 & 6,120 & 37,762 & 101,800 \\
2009 & 10,219 & 25,697 & 35 & 10,566 & 46,517 & 101,200 \\
2010 & 10,878 & 26,823 & 80 & 18,006 & 55,787 & 104,100 \\
2011 & 12,057 & 28,524 & 188 & 25,916 & 66,685 & 98,100 \\
2012 & 12,379 & 30,711 & 268 & 34,077 & 77,435 & 97,300 \\
2013 & 12,656 & 32,969 & 508 & 36,710 & 82,843 & 94,600 \\
2014 & 12,873 & 37,620 & 994 & 37,900 & 89,387 & 100,200 \\
2015 & 13,090 & 41,297 & 3,283 & 39,224 & 96,894 & 97,600 \\
2016 & 13,308 & 45,460 & 4,132 & 40,716 & 103,616 & 96,800 \\
\hline Source: BMWi (2017). & & & & & \\
\hline
\end{tabular}

The expansion of RES capacities causes numerous problems for the electricity system, in particular with respect to grid stability. For instance, because grid operators are obliged by law to treat green electricity preferentially, conventional power plants have to adjust their production downward when demand is low (Römer et al., 2012). In contrast, RES technologies are not obliged to contribute to the balancing of supply and demand, thereby undermining grid stability due to their intermittent electricity generation. In fact, prior to the introduction of the MPS in January 2012, operators of renewable power plants, such as wind turbines and PV systems, had no monetary incentive to cease their electricity 
generation even when prices were negative, as they earned a fixed FIT for each $\mathrm{kWh}$ of green electricity that was fed into the grid. This producer behavior is often described by the formula "produce and forget", indicating that producers of green electricity can be completely oblivious to market signals and electricity demand.

To better align green electricity production with demand, Germany's FIT system for RES promotion was supplemented in 2012 by the MPS to increase the incentives for a demand-orientated generation of green electricity. The aim of this scheme was to encourage operators of RES plants to sell their green electricity to the market, rather than feeding it into the grid at any time, thereby obtaining fixed FITs per $\mathrm{kWh}$. While taking part in the MPS was voluntary and operators of RES plants could switch back and forth between the MPS and the FIT system on a monthly basis, risk-averse RES operators could always stay in the traditional FIT system. ${ }^{1}$

Yet, switching to the MPS is attractive, as the remuneration per kWh may be higher than under the FIT system (Figure 1). Under the MPS, in addition to the spot market price $S P$, plant operators receive a variable premium, called market premium ()MPR). It is calculated ex post on a monthly basis as the difference between the feed-in-tariff FIT and the electricity's technology-specific average market value $M V$ in the previous month. ${ }^{2}$ Not least, RES operators receive a fixed management premium MMP that is intended to cover the costs arising from participating in the market. Thus, under the MPS, total revenues $R$ are given by the sum of three components: $R:=S P+M P R+M M P$, the spot price, the market and the management premium.

Unlike the FIT system, revenues are not guaranteed under the MPS, but are primarily determined by the market. Hence, RES plant operators are exposed to price risks, which in times of high demand may turn out to be positive: If the spot market price $S P$ exceeds

\footnotetext{
${ }^{1} \mathrm{~A}$ prerequisite for participating in the MPS is that plants can be curtailed via remote control.

${ }^{2}$ The market values of electricity generated by various RES technologies differ because of distinct production peaks. For instance, solar electricity production peaks at noon in the summer months, thereby coinciding with high electricity demand and, thus, high prices, whereas wind power frequently peaks at winter nights when demand and prices tend to be lower.
} 
the average market value $M V$ of the previous month, the revenues emerging from the MPS are higher than those from the FIT system (see Figure 1). However, while in the FIT system green electricity production always yields positive revenues, under the MPS, the generation of green electricity may not only yield lower revenues than under the FIT system, but might even turn out to be unprofitable. In fact, recognizing that the marginal cost of production is negligible for renewable technologies such as wind and solar power, if spot market prices are negative, green electricity production is only profitable under the MPS as long as the sum of the market premium $M P R$ and the management premium $M M P$ exceeds the magnitude of the negative spot market price $S P$.

Figure 1: Revenues under Germany's Feed-in Tariff (FIT) System and its Market Premium Scheme (MPS)

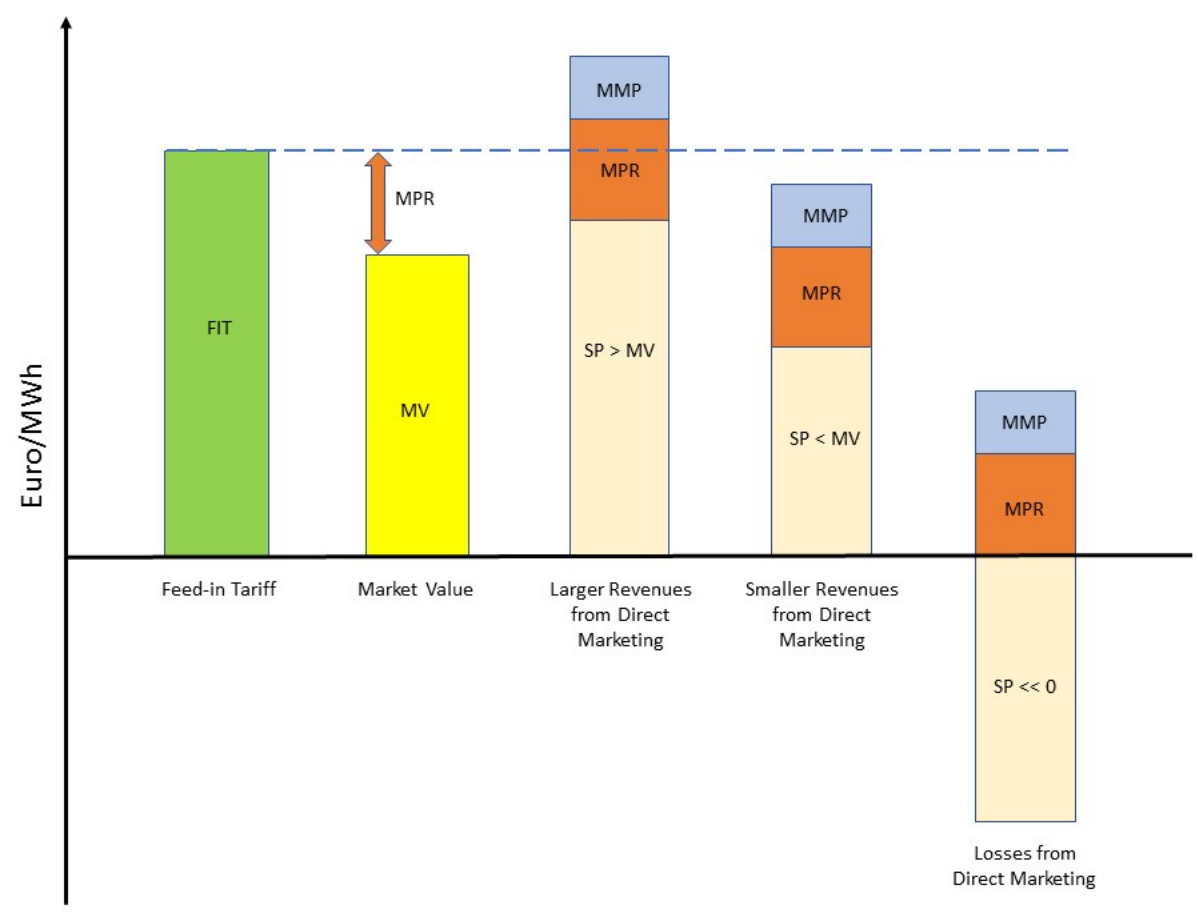

Hence, operators stop feeding green electricity into the grid when the spot market price is substantially below zero so that the losses from direct marketing exceed the premia paid to the operators: $S P+M P R+M M P<0$. Therefore, as was intended with 
establishing the MPS, RES plant operators would curtail their production in response to significantly negative prices. In case of moderately negative prices, however, even under the MPS, producers still have an incentive to feed their green electricity into the grid. In other words, negative electricity prices cannot be entirely avoided by the MPS.

In August 2014, Germany revised the MPS by mandating participation of all new RES plants with a capacity of more than 500 kilowatt $(\mathrm{kW})$, whereas operators of RES plants that were installed prior to August 2014 remained free to choose between the MPS and the FIT system. ${ }^{3}$ To further diminish the frequency of negative prices at the wholesale market, an additional disincentive was established in this MPS reform: If electricity prices are negative for at least six consecutive hours, the market premium for RES plants that came into operation after January 1, 2016, and whose capacity exceeds $500 \mathrm{~kW}$ (3,000 kW in the case of wind power) is defined to equal zero during the entire period with negative prices.

With another reform of its feed-in tariff system that came into force at the outset of 2017, the German government aimed at further increasing the economic efficiency of the RES promotion. To this end, technology-specific tender schemes were established, where participants bid on the intertemporally constant subsidy amount per kWh that they receive when feeding green electricity into the grid. Yet, alternatively, RES operators can still opt for selling their electricity at the market via the MPS. While the reform of 2017 thus should not have affected the occurrence of negative electricity prices, we nevertheless have deliberately restricted our sample to observations prior to this new promotion regime.

As Figure 2 reveals, prior to 2012, just a few operators sold their green electricity at the market. After the introduction of the MPS, though, the share of green electricity that was sold at the market and remunerated via the MPS rapidly increased. Most notably, many operators of onshore wind farms and biomass plants switched immediately to the MPS

\footnotetext{
${ }^{3}$ The capacity threshold of $500 \mathrm{~kW}$ for obligatory participation in the MPS was reduced soon: Since January 1, 2016, all new RES plants with a capacity higher than $100 \mathrm{~kW}$ must participate in the MPS.
} 
in 2012, most likely because of the generous management premium $M M P$. By contrast, only a minority of the PV plant operators opted for the MPS, which is due to the fact that the overwhelming majority of PV systems are installed on the roofs of private houses. ${ }^{4}$

Figure 2: RES Capacities (in Gigawatt, GW) Participating in Germany's Market Premium Scheme (MPS)

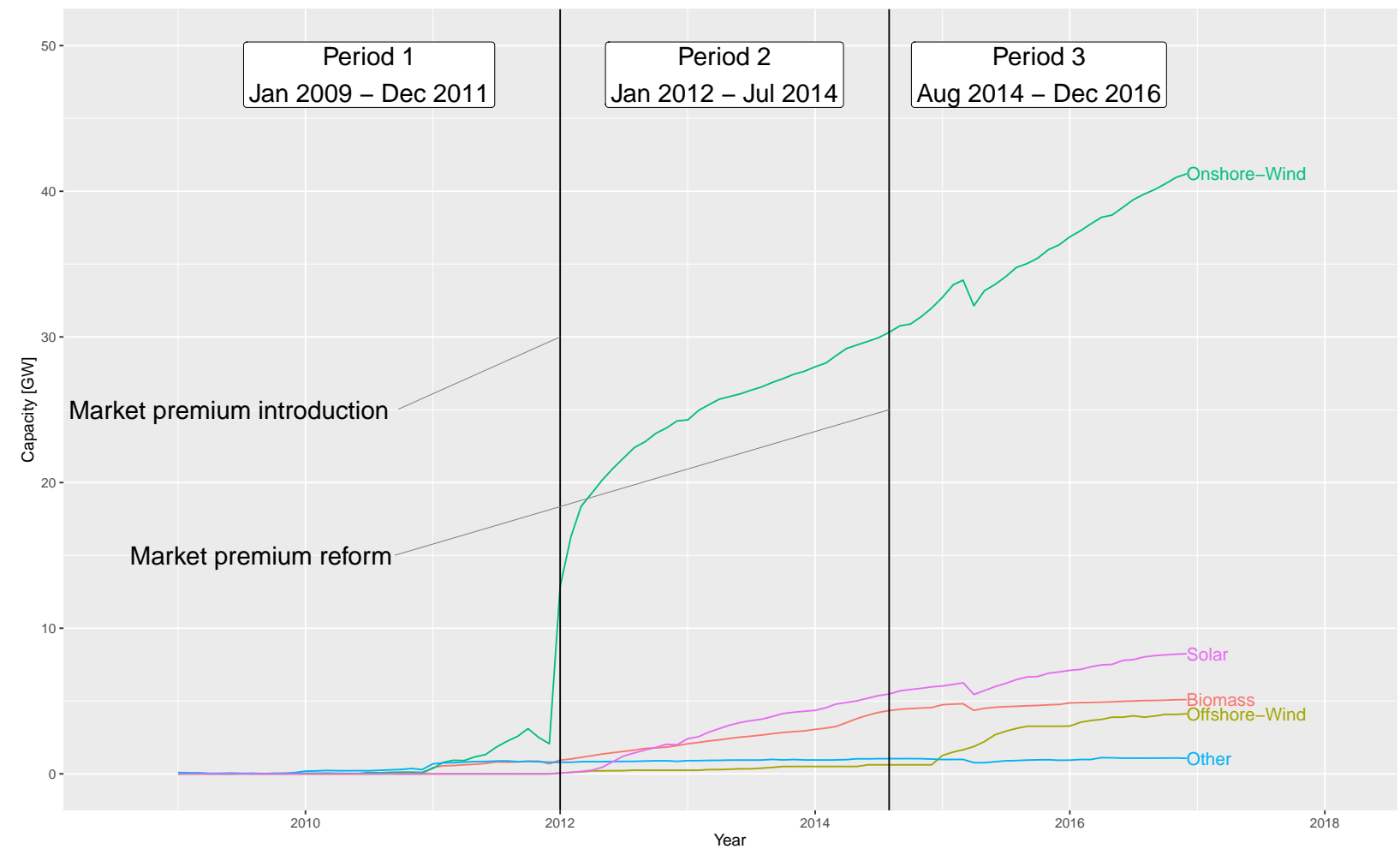

Source: TSO (2018).

\section{Data}

To gauge the impact of the MPS on electricity prices, our research draws on data that covers the period from January 2009 to December 2016 and originates from two sources: the websites of Fraunhofer (2018) and the European Energy Exchange (EEX,

\footnotetext{
${ }^{4}$ The kink in participation in the MPS in early 2015 is due to the obligation to dispose of a remote control that was introduced in 2015. As of 2015, plants operators who did not install such a device were not allowed to sell their electricity directly anymore.
} 
https://www.eex.com). From the EEX, we retrieved the price of the EU emission allowances, which represents an important control variable, as well as the Physical Electricity Index (Phelix). This index serves as the dependent variable in our analysis and measures the hourly electricity spot market price.

The key explanatory variables are the hourly electricity generation of wind and solar power plants. Additional control variables are, among others, the hourly demand load and the electricity generation from conventional sources. Not least, we control for various patterns of seasonality by including the hour of the day, the day of the week, the day of the year, and the calendar month.

In line with the timing of the launch of Germany's MPS in 2012 and its reform in August 2014, we divide our data base into three disjunct periods: Period 1 spans from January 2009 to December 2011, that is, the time period prior to the introduction of the MPS. Period 2 ranges from January 2012 to July 2014, that is, the period between the introduction and the reform of the MPS, and Period 3 spans from August 2014 to December 2016, that is, the time period after the reform of the MPS and the launch of the tendering system for PV and wind power installations in Germany in 2017.

In the period spanning from January 2009 to December 2016, about 17\% of Germany's electricity demand load was covered by wind and solar power plants, with capacities averaging 6,412 and 3,174 Megawatt (MW), respectively (Table 2). Yet, there was substantial inter-temporal variation due to the intermittent character of both technologies. For instance, 25,643 hours elapsed without any feed-in from solar power plants, while another 665 hours saw solar electricity production exceeding that of power plants fired by lignite and hard coal.

Between January 2009 and December 2016, hourly electricity prices averaged 38.5 euros per Megawatthour (MWh), but exhibited substantial volatility, as they ranged from -500 to 210 euros. In 464 hours, negative prices emerged, 98 hours in Period 1, 146 hours in Period 2, and 220 hours in Period 3. Given the total number of 61,320 hours in the 
Table 2: Summary Statistics for the Time Period January 2009 to December 2016

\begin{tabular}{lcccccc}
\hline Variable & & & & & & Observation \\
\hline Phelix (EUR/MWh) & 38.54 & 16.67 & -500.0 & 210.0 & 69,527 & hourly \\
Allowance price (EUR/t CO2) & 9.10 & 4.06 & 3.02 & 16.84 & 2,511 & daily \\
Solar power plants (MW) & 3,174 & 5,171 & 0 & 28,323 & 60,434 & hourly \\
Wind power plants (MW) & 6,412 & 5,798 & 0 & 34,078 & 60,434 & hourly \\
Lignite power plants (MW) & 15,760 & 2,169 & 0 & 20,940 & 60,434 & hourly \\
Hard coal power plants (MW) & 11,539 & 5,436 & 0 & 22,298 & 60,434 & hourly \\
Nuclear power plants (MW) & 11,096 & 2,640 & 0 & 18,506 & 60,765 & hourly \\
Load (MW) & 56,095 & 10,383 & 29,201 & 81,109 & 60,765 & hourly \\
\hline
\end{tabular}

period spanning 2009 to 2016, the occurrence of negative prices was rather seldom, yet clearly increasing over time (Figure 3). Negative prices most likely occur when electricity demand is low, primarily at holidays (Figure 3) and in the early morning hours (Figure 5). In fact, around half of the number of hours with negative prices fell between midnight and 5 a.m.

Figure 3: Hourly Spot Market Electricity Prices for Germany between 2009 and 2016 Reflected by the Physical Electricity Index (Phelix)

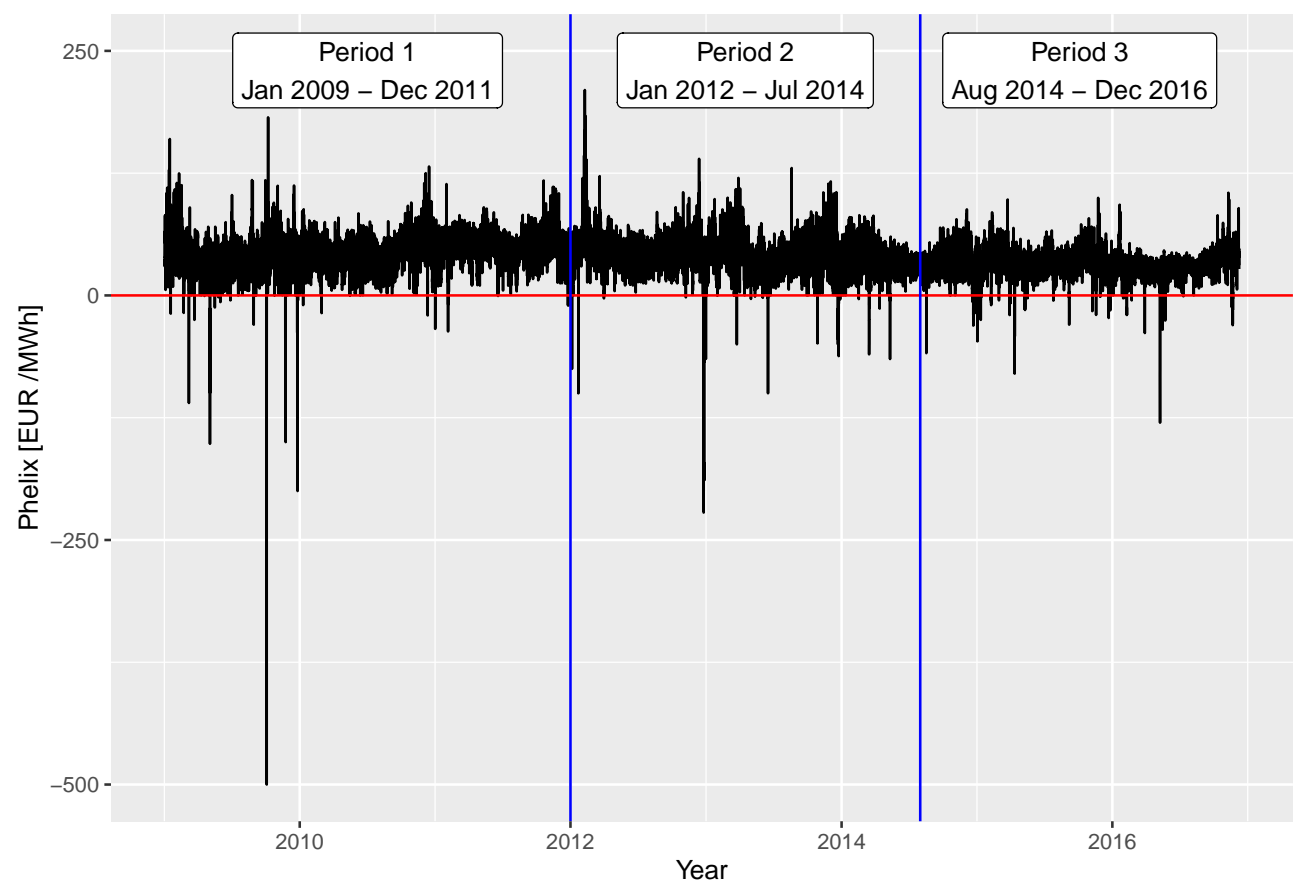


Figure 4: Daily Spot Market Electricity Prices for Germany between 2009 and 2016 given by the Physical Electricity Index (Phelix)

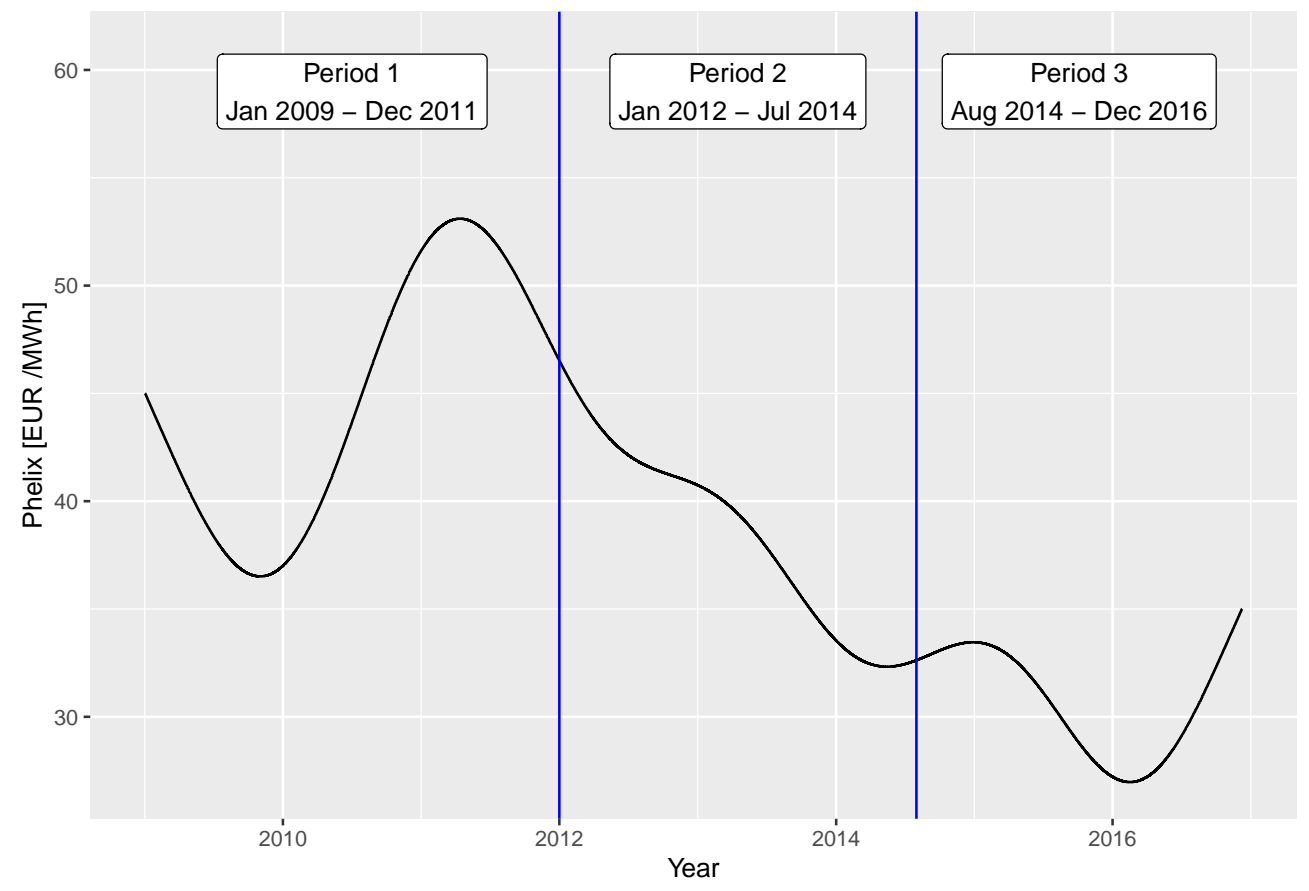

Figure 5: Within-Day Distribution of the Frequency of Hours with Negative Prices in Percent

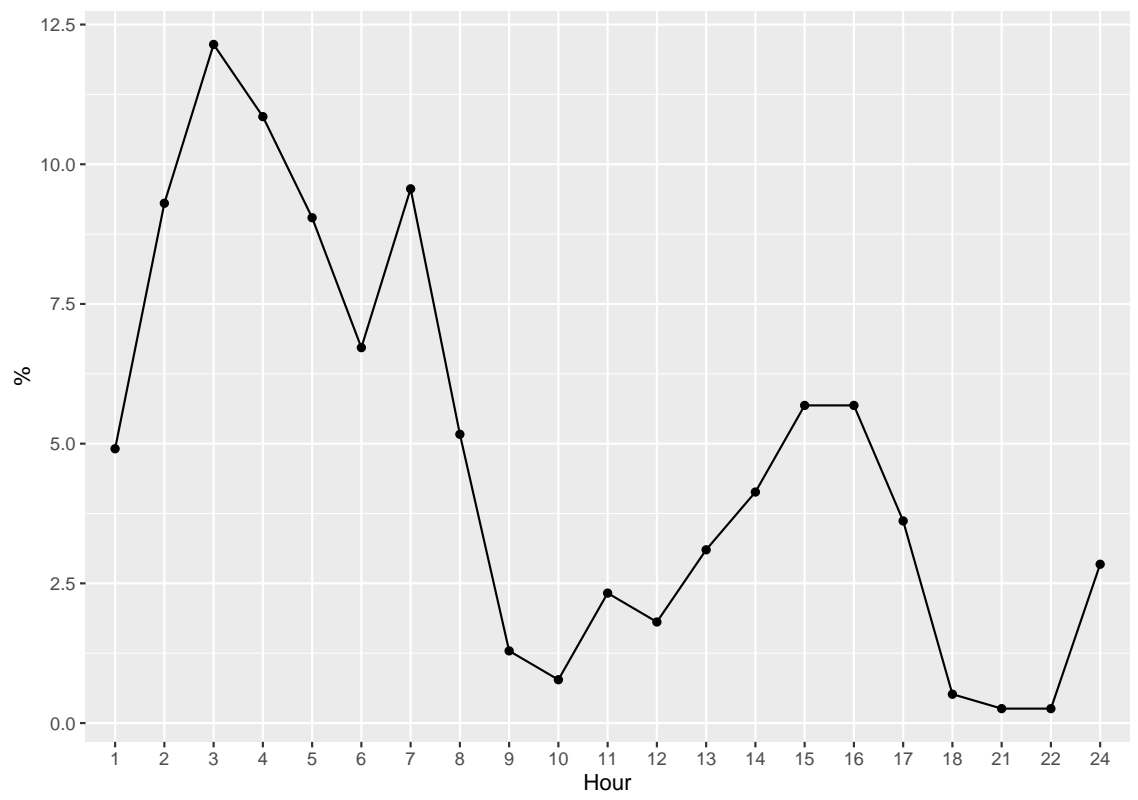

From Period 1 to Period 3, there was a declining trend in electricity prices (Figure 4): Prices peaked at about 55 euros per MWh in mid-2011 due to the sudden shutdown of 
about half of Germany's nuclear power plants in the aftermath of the accident in Japan's Fukushima, then fell to 25 euros per MWh at the outset of 2016, but recovered afterwards. In fact, the period after the launch of the MPS and before its reform in August 2014 (Period 2 ) is characterized by a downward drift in prices. Overall, in Period 3, electricity prices were lowest and their distribution was tightest (Figure 6).

Figure 6: Distribution of the Physical Electricity Index (Phelix, in Euro per Megawatthour) by Periods

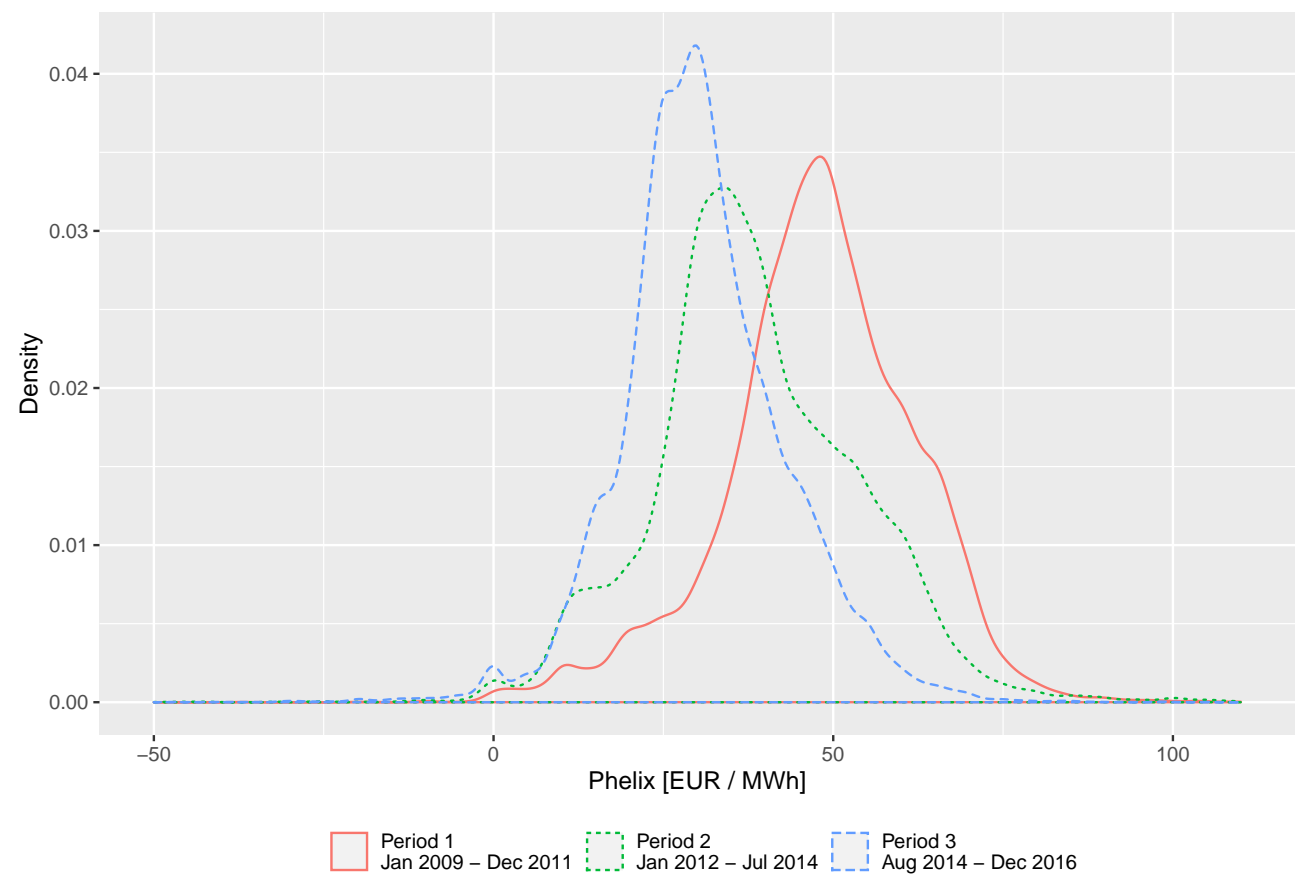

\section{Method}

The effect of green electricity generation on electricity prices has been typically estimated on the basis of time series models - see, for instance, Fanone et al. (2013); Gerster (2016); Ketterer (2014); de Lagarde and Lantz (2018); Paschen (2016). This approach necessitates the specification of a functional form that models the relationship between prices and key variables, such as hour of the day, as well as a set of covariates. In contrast, we apply a nonparametric method called Bayesian Additive Regression Trees (BART) that 
requires less guess-work in model fitting. Actually, a key advantage of the BART method is that there is no necessity to specify a parametric form for the conditional expectation $E\left[p_{t} \mid \boldsymbol{z}_{t}\right]$ of the dependent variable, where in our example $p_{t}$ denotes the price of electricity in hour $t$ and $z_{t}$ designates the vector of covariates.

Furthermore, BART methods are particularly appropriate for identifying complex interactions between covariates and, hence, effect heterogeneity (Hill, 2011). This is most relevant in the context of determining the effect of the MPS on on electricity prices given that electricity demand load, as well as green electricity generation, highly vary over time, making dummies for the day of the week and the hour of the day, as well as interaction terms of these variables, indispensable model ingredients. Another advantage is that, owing to the high flexibility of the model, predictions from BART models are highly precise - see for instance the empirical examples provided by Hill (2011), as well as our own results presented below. Not least, rather than estimating numerous separate models, for instance for each hour of a day individually, for both peak- and off-peak hours (see e. g. Gerster, 2016), a single BART model suffices for our analysis.

The basic idea of the BART modeling strategy is to explain the outcome variable, in our cases electricity prices $p_{t}$, by a large number $L$, say $L=200$, of regression trees:

$$
p_{t}=\sum_{l=1}^{L} f\left(\boldsymbol{z}_{t} \mid \boldsymbol{\theta}_{l}\right)+u_{t},
$$

where $u_{t} \sim N\left(0, \sigma^{2}\right) . f\left(\boldsymbol{z}_{t} \mid \boldsymbol{\theta}_{l}\right)$ is called tree function and $\boldsymbol{\theta}_{l}$ denotes a parameter vector that describes tree $l$ - see Breiman (2001) for an introduction to tree- and forest-based methods. Each tree $l$ explains a part of the variation in the dependent variable $p_{t}$ using only a subset of the covariates. If a tree refers to a single covariate, it captures a main effect, otherwise a tree reflects the effects of two or more covariates and their interaction. The high flexibility of BART results from the potentially large number of trees with which any sort of interaction between covariates can be modeled. 
As an illustration, Figure 7 presents an example of a single tree, where at the first interior node $n_{1}$ all observations with $z_{1}<0.4$ are attributed to the left branch, ending in terminal node $n_{2}$. The right branch divides observations further according to the decision rule $z_{2}<0.7$, resulting in terminal nodes $n_{4}$ and $n_{5}$. Formally, a tree of size $s$ is defined by a node vector $\boldsymbol{n}:=\left(n_{1}, \ldots, n_{j}, \ldots, n_{s}\right)^{\top}$ consisting of both interior and terminal nodes. To each interior node, a threshold $c_{j}$ is associated that implies a decision rule on how to traverse the tree: If $z_{i t}<c_{j}$, observation $z_{i t}$ is sent left, if $z_{i t} \geq c_{j}$, it is sent right in the tree. Thresholds are determined a posteriori on the basis of the observations on the covariates. Each terminal node is associated with a parameter $\mu_{k}$, representing the mean outcome of the subgroup of observations that are attributed to that terminal node. Gathering mean outcomes in vector $\boldsymbol{\mu}:=\left(\mu_{1}, \ldots, \mu_{f}\right)^{\top}$, where $f$ is the number of terminal nodes, and defining $c:=\left(c_{1}, \ldots, c_{g}\right)^{\top}$, where $g$ indicates the number of internal nodes, the parameter vector $\boldsymbol{\theta}_{l}:=\left(\boldsymbol{c}_{l}^{\top}, \boldsymbol{n}_{l}^{\top}, \boldsymbol{\mu}_{l}^{\top}\right)^{\top}$ determines the tree function $f\left(\boldsymbol{z}_{t} \mid \boldsymbol{\theta}_{l}\right)$ of tree $l$.

Figure 7: Illustration of a Regression Tree
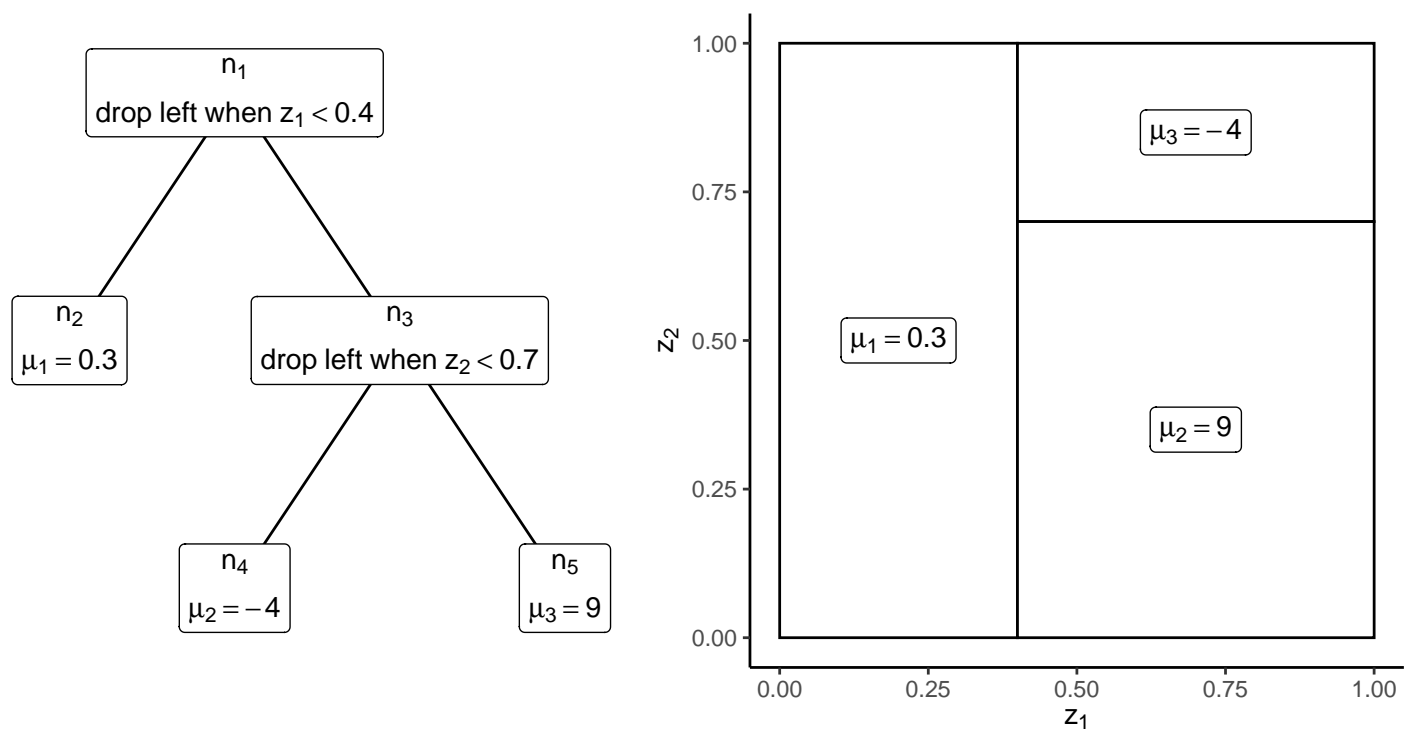

The illustration depicts a tree of size 3 for function $f\left(z_{1}, z_{2}\right)=0.3 I\left[z_{1}<0.4\right]+9 I\left[z_{1} \geq 0.4\right] I\left[z_{2}<0.7\right]-4 I\left[z_{1} \geq 0.4\right] I\left[z_{2} \geq 0.7\right]$, where $I[$.$] equals one if the condition in brackets is met. The left panel shows the tree in terms of nodes, where with each interior$ node $n_{1}$ and $n_{3}$, a decision rule is associated. The terminal nodes $n_{2}, n_{4}$, and $n_{5}$ are associated with mean outcomes, displayed in the partition in the right panel. 
To provide intuition for the BART modeling approach, consider taking the fit $f\left(\boldsymbol{z}_{t} \mid \boldsymbol{\theta}_{1}\right)$ from the first tree and subtracting it off from the observed outcome $p_{1}$ to form residuals. Then imagine fitting the next tree to these residuals, each tree contributing to the overall fit. This process would be performed many times, thereby ever improving the overall fit. While improving the overall fit by adding tree by tree, however, one wants to avoid overfitting. To counter overfitting, Chipman et al. (2010) propose regularization priors, such as prior distributions to penalize the number of nodes and the means of each component tree. For instance, the prior for the number of nodes puts most probability mass on trees with two interior nodes, while still allowing larger trees if it is necessitated by the data. The typical prior for the thresholds assigns each observed value the same probability.

To estimate the effect of the introduction of the MPS in 2012, as well as of its reform in August 2014, we split the data set into the three time periods described in the previous section and define the following potential outcomes in terms of prices:

$$
p_{t}^{s}(r)= \begin{cases}p_{t}^{s}(1) & \text { Regime 1: Absence of the MPS } \\ p_{t}^{s}(2) & \text { Regime 2: Prevalence of the MPS } \\ p_{t}^{s}(3) & \text { Regime 3: Prevalence of the Revised MPS }\end{cases}
$$

where $p_{t}^{s}(r)$ denotes the price of electricity in hour $t$ under Regime $r$ in Period $s$. As presented in Definition (2), there are three regimes that emerge in a natural way due to the launch and revision of the MPS. Given our focus on the frequency with which negative prices occur, to estimate the effect of the MPS, in principle, we would like to calculate the difference between the actual frequency of negative prices in Period 2 and the hypothetical frequency in the counterfactual situation of an absence of the MPS (Regime 1).

When employing BART to estimate the effect of the MPS, we follow Imbens and Rubin (2015) and, for each draw $\boldsymbol{\theta}_{m}$ from the posterior distribution of tree parameter vector $\boldsymbol{\theta}$, we simulate potential outcomes for the prices $p_{t}^{s}(r)$ that pertain to all nine combinations of 
regimes and periods. Altogther, we draw $M=3,000$ parameter vectors $\boldsymbol{\theta}_{1}, \ldots, \boldsymbol{\theta}_{M}$ from the posterior distribution, noting that our empirical results remain largely unchanged when $M$ is larger than 3,000 . Based on these price simulations, we then compute the number of hours with negative prices in Period $s$ under Regime $r$ :

$$
\sum_{t \in \text { Period } s} I\left[p_{t}^{s}(r)<0\right]
$$

where indicator function $I\left[p_{t}^{s}(r)<0\right]$ indicates the occurrence of a negative price in hour $t$. Taking respective differences in the number of negative hours across regimes yields the effects $\tau$ of introducing and revising the MPS. For instance,

$$
\tau^{2}(1):=\sum_{t \in \text { Period } 2} I\left[p_{t}^{2}(1)<0\right]-\sum_{t \in \text { Period } 2} I\left[p_{t}^{2}(2)<0\right]
$$

reflects the effect of the MPS (Regime 2) relative to Regime 1 (absence of MPS). A positive value of $\tau^{2}(1)$ would indicate that the introduction of the MPS is associated with less hours with negative prices. Repeating this exercise $M=3,000$ times, we ultimately get an estimate $\widehat{\tau^{2}(1)}:=M^{-1} \sum_{m=1}^{M} \tau_{m}^{2}(1)$ of the effect of the introduction of the MPS in Period 2 by taking the mean of the differences $\tau^{2}(1)$. Finally, the lower and upper bounds of the posterior intervals of the BART estimator are given by the 2.5th and 97.5th percentiles of the sequence of $M=3,000$ estimates $\tau_{1}^{2}(1), \ldots, \tau_{M}^{2}(1)$.

\section{Results}

Figure 8 indicates that our empirical approach, for which we have used the R package BART (McCulloch et al., 2018), is highly appropriate: the within-sample predictions of electricity spot prices on the basis of BART are dramatically better than those based on a standard OLS regression model, most notably with respect to extremely high prices and negative price spikes (see Figure 8). This comparison highlights the value added of using 
BART for our analysis, where the primary interest is on the occurrence of negative prices. Along with the quite high fit of $R^{2}=0.94$, this prediction performance is all the more remarkable, as the share of hours with negative prices is less than $1 \%$ in the period 2009 to 2016 .

Figure 8: Comparison of the Within-sample Predictions of Electricity Spot Prices of the Bayesian Additive Regression Tree (BART) Method with those of a Standard OLS Regression

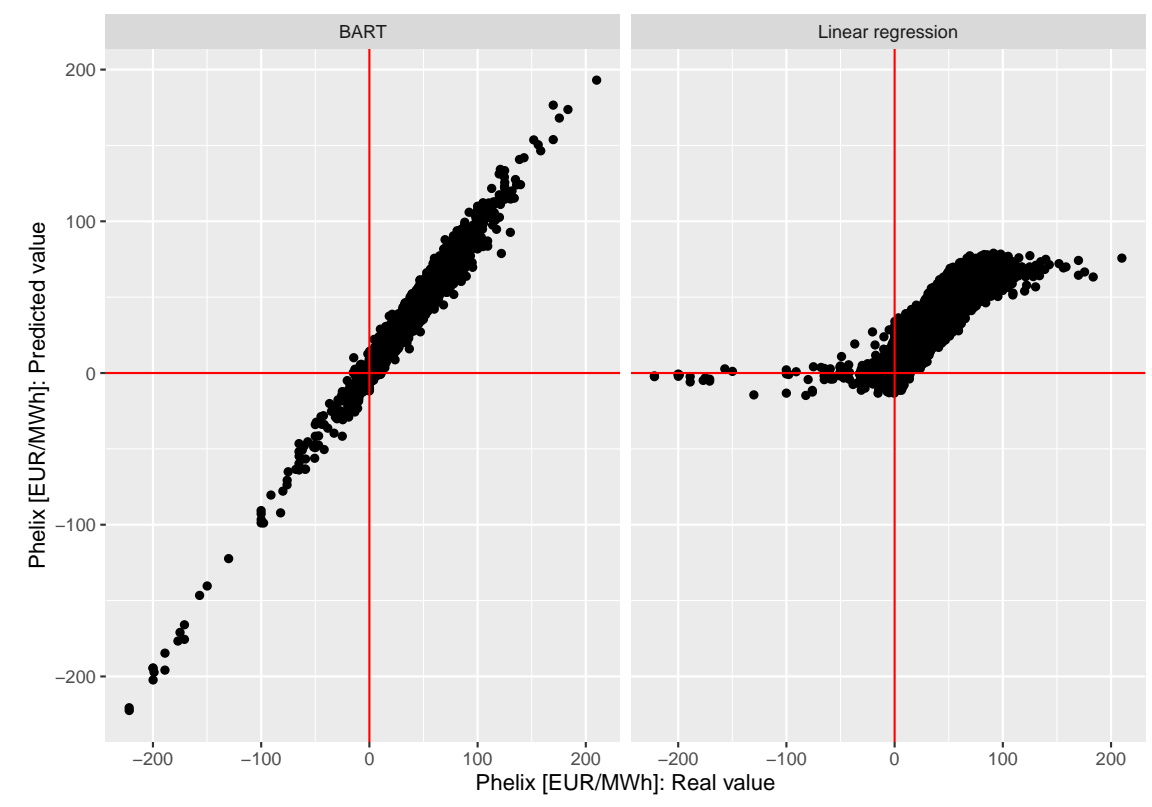

Given the time trends appearing from Figure 4, in what follows, we eliminate such trends by subtracting a smooth time trend $\widehat{f(t)}$, estimated using regression splines, from the observed values $w_{t}: \tilde{w}_{t}=w_{t}-\widehat{f(t)}$, where $w$ stands for the dependent or any explanatory variable. Figure A2 of the appendix illustrates that the detrended covariates overlap much more than the original covariates (see Figure A1). Moreover, in accord with Figure 8 , Figure $\mathrm{A} 3$ of the appendix demonstrates that the BART model with the detrended variables also outperforms a standard linear OLS model with respect to the within-sample prediction of negative prices.

Figure 9 presents further evidence on the high accuracy of BART predictions. The predicted number of hours with negative prices amounts to some 153 and 226 for Period 
2 and 3, respectively, while the actual numbers amount to 146 and 220, respectively (see the horizontal lines in Figure 9). The efficacy of the MPS with respect to avoiding negative prices is strongly corroborated by the effect estimate of $\widehat{\tau^{3}(1)}=561$ hours, which is accompanied by a relatively tight $95 \%$ posterior interval of $[512,609]$. In other words, Germany's MPS helped to avoid 561 hours with negative prices. This corresponds to some $70 \%$ of the almost 790 hours with negative prices that would have occurred in Period 3 in the absence of the MPS - see the prediction for Regime 1 in the right panel of Figure 9.

Likewise, given that the counterfactual number of hours with negative prices under Regime 1 is estimated at about 380 and the predicted number for Period 2 is 153 (see the left panel of Figure 9), the lauch of the MPS in 2012 helped to reduce the number of hours with negative prices in Period 2 by $\widehat{\tau^{2}(1)}=227$, with a posterior interval of $[182,266]$. In other words, due to the introduction of the MPS, roughly half of the number of hours with negative prices could be avoided in Period 2. Lastly, the effect of reforming the MPS in August 2014 is estimated at $\widehat{\tau^{3}(2)}=246$ hours in which negative prices could be avoided, with a posterior interval of $[213,279]$.

Figure 9: Number of Hours with Negative Prices in the Aftermath of the Launch of the German Market Premium System in 2012 and its Reform of August 2014

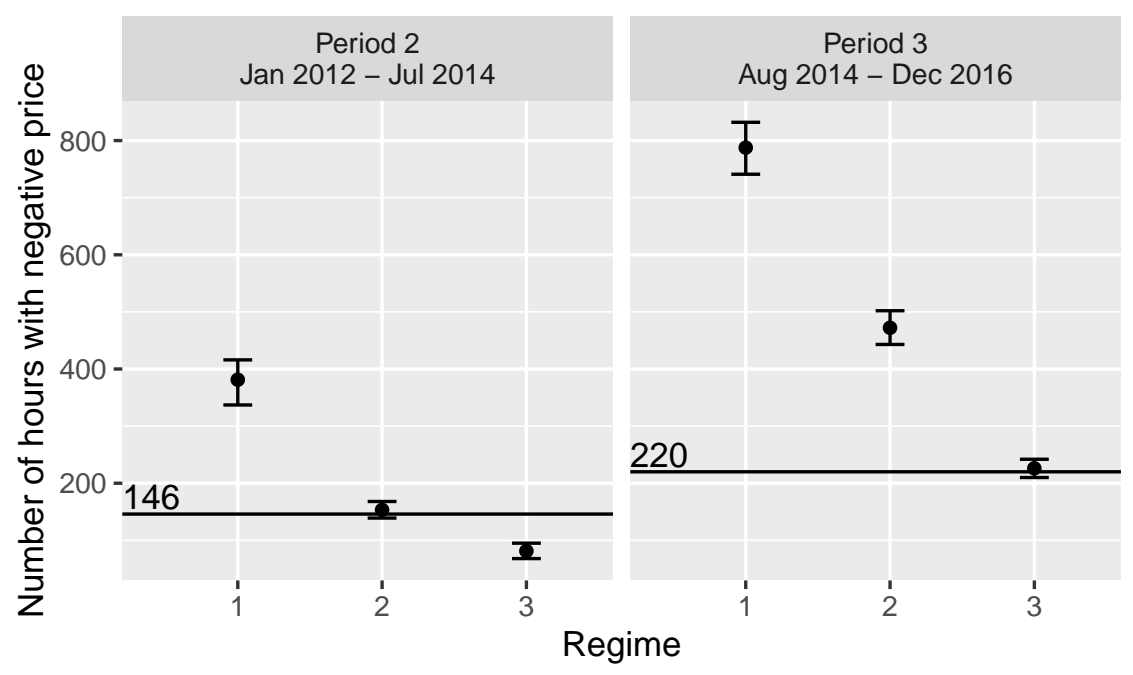


It also bears noting that the MPS helped to avoid strongly negative prices. For instance, Figure 10 indicates that the reform of the MPS was successful in avoiding about 200 negative prices of less than -20 euros per Megawatthour (MWh). In this case, the effect of the reform, denoted by $\xi^{3}(2):=\sum_{t} I\left[p_{t}^{3}(3)<-20\right]-\sum_{t} I\left[p_{t}^{3}(2)<-20\right]$, amounts to $\widehat{\xi^{3}(2)}=196$ hours, with a posterior interval of $[163,228]$. Accordingly, for the introduction of the MPS, we estimate an effect of $\widehat{\xi^{2}(1)}=32$ hours, with $[19,35]$ being the posterior interval.

Figure 10: Number of Hours with Prices below -20 Euros per Megawatthour in the Aftermath of the Launch of the German Market Premium System in 2012 and its Reform of August 2014

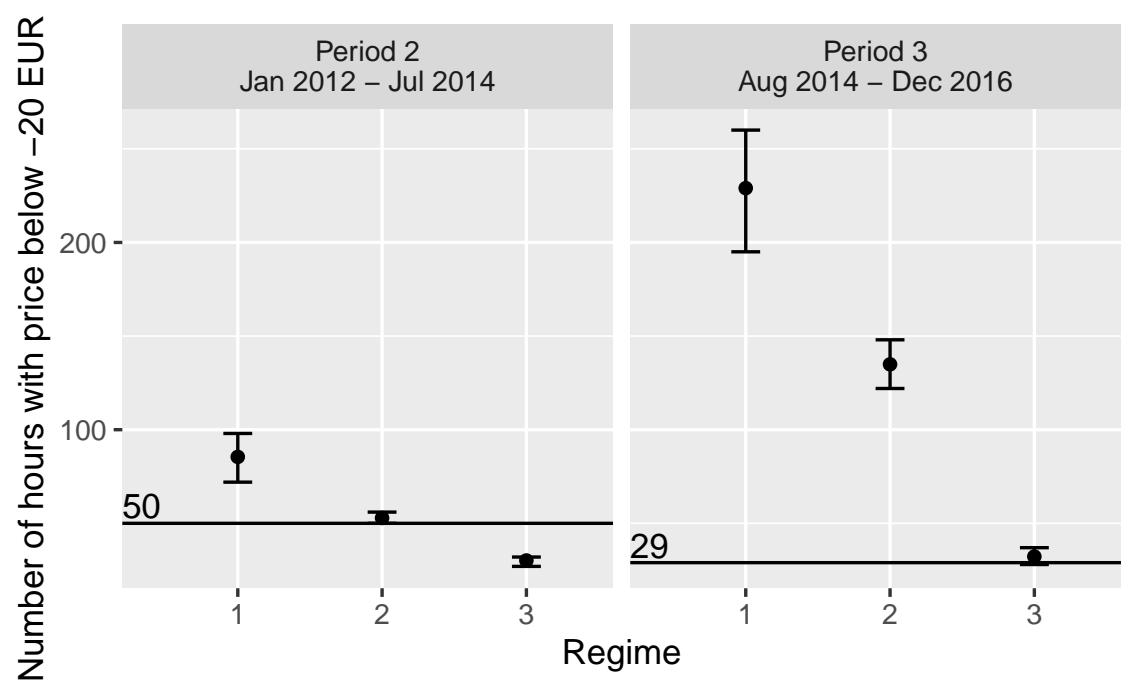

For illustration purposes, by hours of the day, Figure 11 provides a detailed picture of the number of hours in which negative prices could have been avoided. This figure, which results from taking the difference between the counterfactual and the actual number of hours with negative prices, demonstrates that at 5 a.m., negative prices have been avoided by the MPS almost 70 times in Period 3 (see the right panel of Figure 11). Furthermore, the panel on the left-hand side of Figure 11 suggests that if the MPS had not been implemented, Period 2 would have experienced more than 30 additional days with negative prices at $5 \mathrm{a} . \mathrm{m}$. The panel in the middle of Figure 11 indicates that the reform of the MPS helped to avoid 27 additional days with negative prices at 5 a.m. This finding 
Figure 11: Number of Hours with Avoided Negative Prices calculated by taking the Difference between the Counterfactual and the Actual Number of Hours with Negative Prices, by Hour and Period

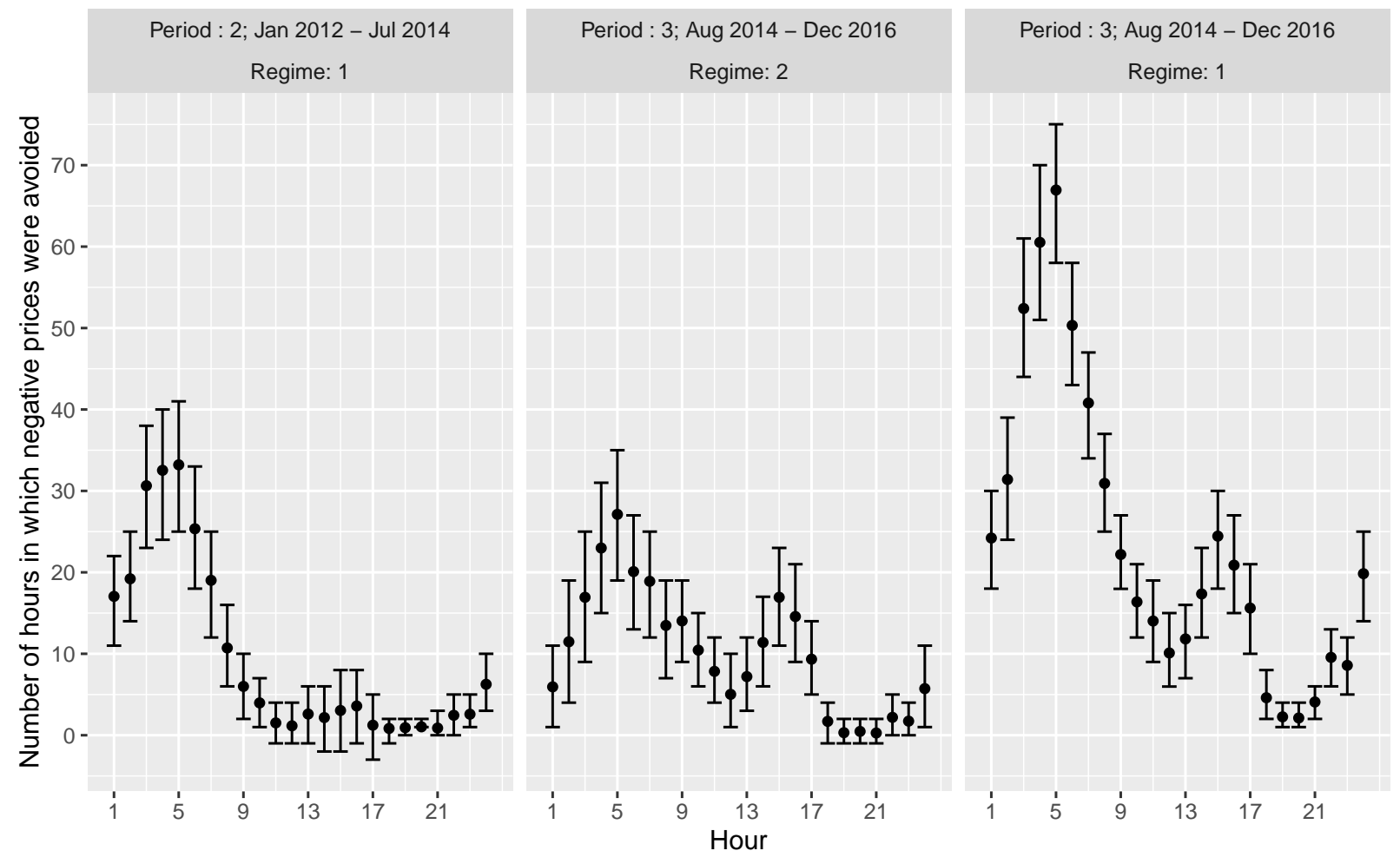

substantiates the above result that the MPS reform has been effective in further aligning the production of green electricity with market signals.

Finally, we conduct two robustness checks whose results are reported in the appendix. First, instead of detrending the variables by using regression splines, as in our previous analysis, we take first differences. Instead of changes in the frequency of negative prices, the results from this exercise, displayed in Figure A4, reflect short-term price changes. The results confirm our findings displayed in Figure 11: The differences between counterfactual and actual electricity prices are among the highest in the early hours of a day. As this is the time period when most negative prices occur (Figure 5), we conclude that the MPS was successful in avoiding negative prices.

Second, we take into account the integration of Germany into the European electricity market in November 2010, which may have had a bearing on the occurrence of negative 
electricity prices. ${ }^{5}$ Accordingly, we split Period 1 into two subperiods: Period 1a (January 2009 - October 2010) and Period 1b (November 2010 - December 2011). The results of this robustness check indicate that if the MPS had not been in operation in Period 2 (January 2012 - July 2014), negative prices would have occurred in about 450 hours, while the actual value amounts to 146 hours (lower left panel of Figure A5). Even though the point estimates of the number of negative prices are somewhat higher than in Figure 9, the absence of differences between Period 1a and Period $1 \mathrm{~b}$ indicates that this market coupling event had virtually no impact on the occurence of negative prices.

In addition, if the reform of the MPS had not taken place, we would have observed even more hours with negative prices in Period 3 (see lower right panel of A5). As the estimate of around 800 hours with negative prices from Figure 9 roughly lies in the middle between the two estimates for Regimes 1a and 1b, we conclude that Germany's integration into the European electricity market did not have any bearing on the occurrence of negative prices. This conclusion is substantiated by the evidence displayed in Figure A6, where we focus on negative prices below -20 euros per MWh.

\section{Summary and Conclusion}

To reduce greenhouse gas emissions, an overwhelming number of countries promote renewable energy technologies, most often, as in Germany, in the form of feed-in tariffs (FITs). These tariffs are paid for each $\mathrm{kWh}$ of green electricity produced by renewable energy technologies irrespective of whether the demand for electricity is low. In terms of RES capacity expansion, Germany's FIT system, established in 2000, proved highly successful and is thus widely seen as a role model for the promotion of renewable energy

\footnotetext{
${ }^{5}$ The coupling of European electricity markets started in 2006 when Belgium, France, and the Netherlands connected their electricity markets. Germany and Luxembourg joined this common market area in November 2010. In the meantime, more countries were connected to the common electricity market, such that the coupled market area covers more than 20 countries, standing for about $90 \%$ of Europe's electricity consumption (Ringler et al., 2017). The idea behind market coupling is to increase welfare by allowing electricity to flow from low cost areas to high cost areas, resulting in price convergence (Keppler et al., 2016).
} 
technologies. Between 2000 and 2016, RES capacities increased tenfold to reach 104 GW, thereby exceeding the capacity of conventional power plants in 2016 for the first time (BMWi, 2017). As a consequence of the increasing RES capacities, prices on the wholesale electricity market decreased, which is commonly referred to as merit-order effect (Praktiknjo and Erdmann, 2016). In times of low demand, such as on Sundays and public holidays, the pressure on electricity prices due to a large supply of green electricity may be so strong that prices turn out to be even negative.

To counteract these adverse effects, numerous countries have implemented premium schemes with the aim of aligning green electricity generation with market signals. Under premium schemes, rather than getting fixed FITs (RES, 2018), operators of renewable plants are commonly paid a bonus on top of the wholesale electricity price, thereby providing incentives to reduce production in times of low electricity demand.

In this paper, using hourly day-ahead spot market prices from 2009 to 2016 and the nonparametric method of Bayesian Additive Regression Trees, we have analyzed the efficacy of Germany's MPS in terms of reducing the frequency of hours with negative prices. This method allows for the straightforward construction of counterfactual situations and predictions of hypothetical outcomes, such as the electricity prices in the absence of the MPS. Along with a very high predictive power, this constitutes a distinctive feature of this method (Hill, 2011).

Based on such counterfactual analyses, we find that the implementation of the MPS in Germany in 2012 was quite effective in reducing the prevalence of negative electricity prices. Altogether, the introduction of the MPS and its reform in August 2014 helped to avoid some 560 hours with negative prices in the period spanning January 2012 to December 2016, particularly in the morning hours. Without the MPS, negative prices would have occurred over almost 790 hours, indicating that about $70 \%$ of potential hours with negative prices were avoided. Moreover, the MPS was successful in avoiding about 200 hours with negative prices of less than -20 euros per Megawatthour. Given these results, 
we conclude that, compared to feed-in tariff systems with guaranteed fixed payments per kilowatthour, the market premium system is the more cost-effective measure to promote renewable energy technologies.

It bears noting, though, that a comprehensive cost-benefit analysis would also take into account the implementation and transaction costs that arise due to a MPS. Moreover, while it is beyond the scope of our analysis to provide any guidance on how to design optimal promotion systems, Andor and Voss (2016) suggest that if positive externalities arise from the installation of renewable capacities, capacity-based instruments, such as tax cuts, should be employed, whereas generation-based instruments, such as FITs, would be preferable when positive externalities arise from the generation of green electricity. Yet, although capacity-based subsidies are particularly suited to push new technologies, such promotion schemes have not been implemented in many countries so far. While this also holds true for Germany, the country has recently improved the cost efficiency of the promotion of renewable technologies by introducing a tendering scheme in 2017, in which participants bid on a fixed remuneration per kilowatthour of green electricity, but are allowed to gain additional profits by direct marketing. 


\section{A Appendix}

Figure A1: Overlap in the Covariates across Time Periods

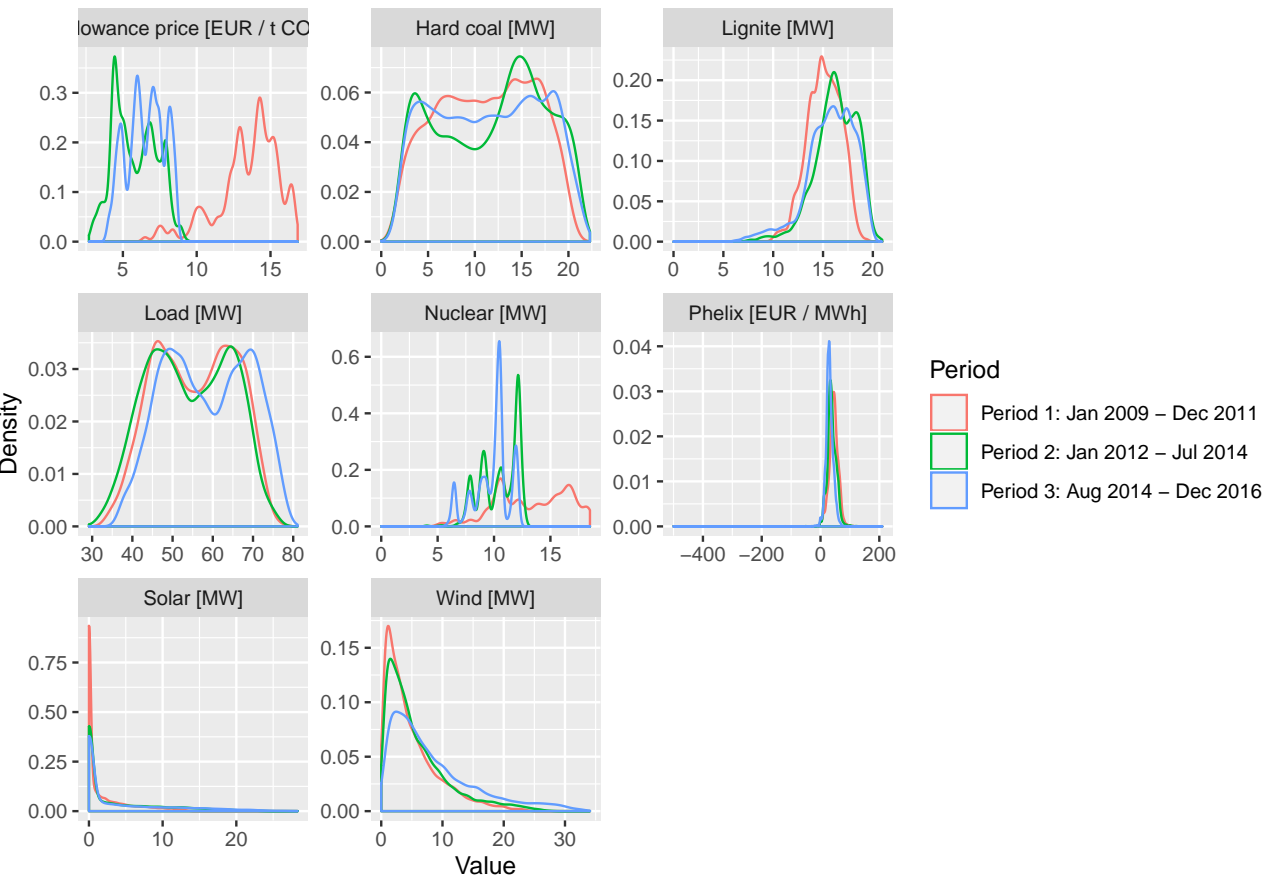

Figure A2: Overlap in the Detrended Covariates across Time Periods
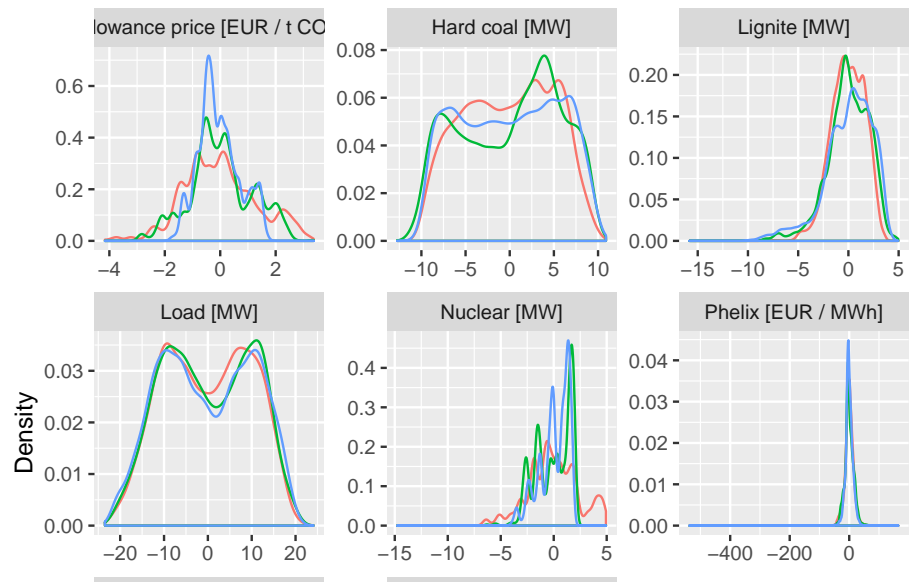

Period

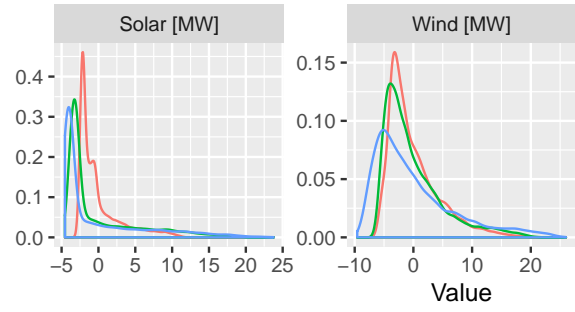


Figure A3: Comparison of the Within-sample Predictions of Electricity Spot Prices of the Bayesian Additive Regression Tree (BART) Method with those of a Standard OLS Regression

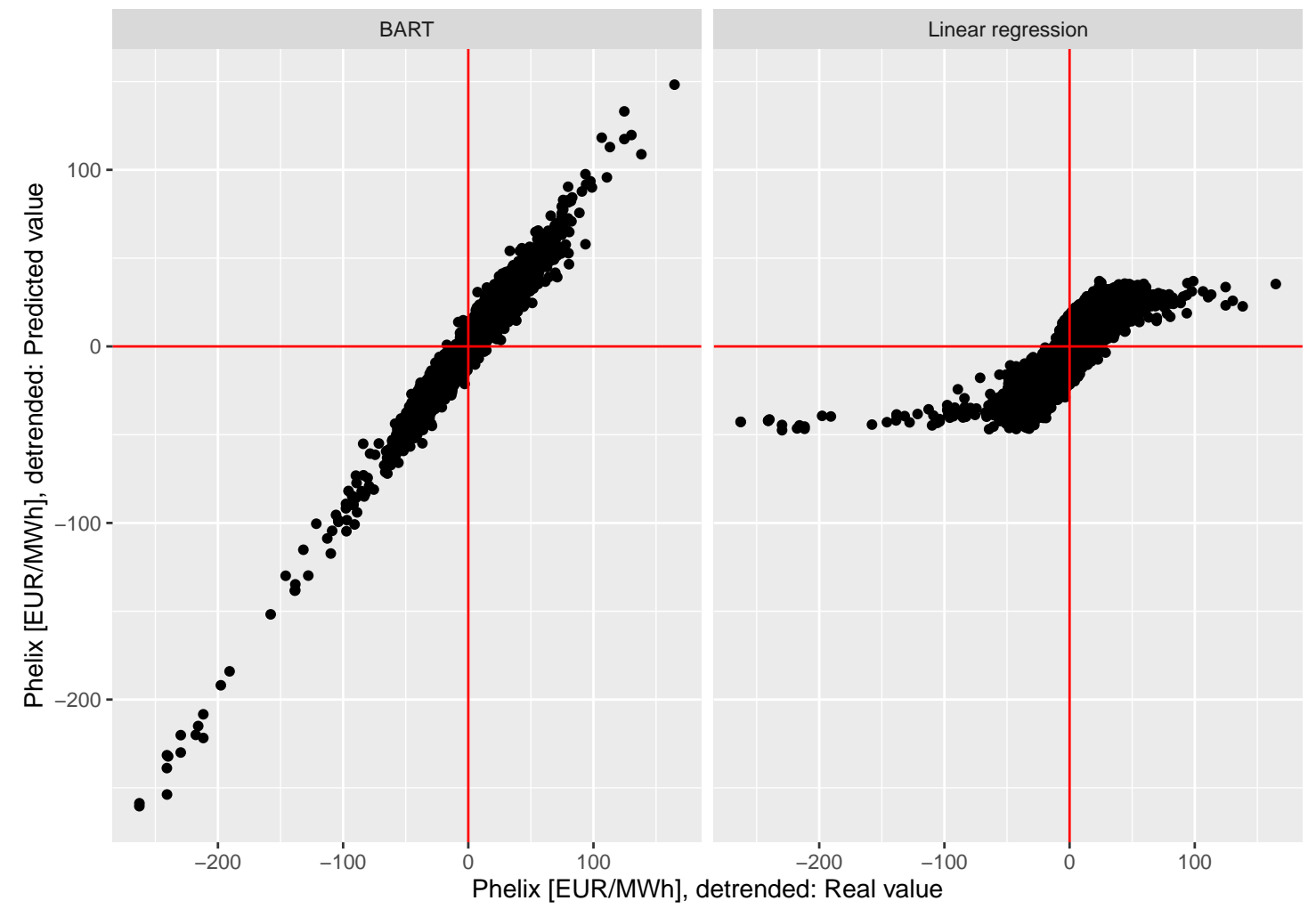


Figure A4: Robustness Check using Differenced Variables: Difference between Counterfactual and Actual Electricity Prices, by Hour of a Day and Period

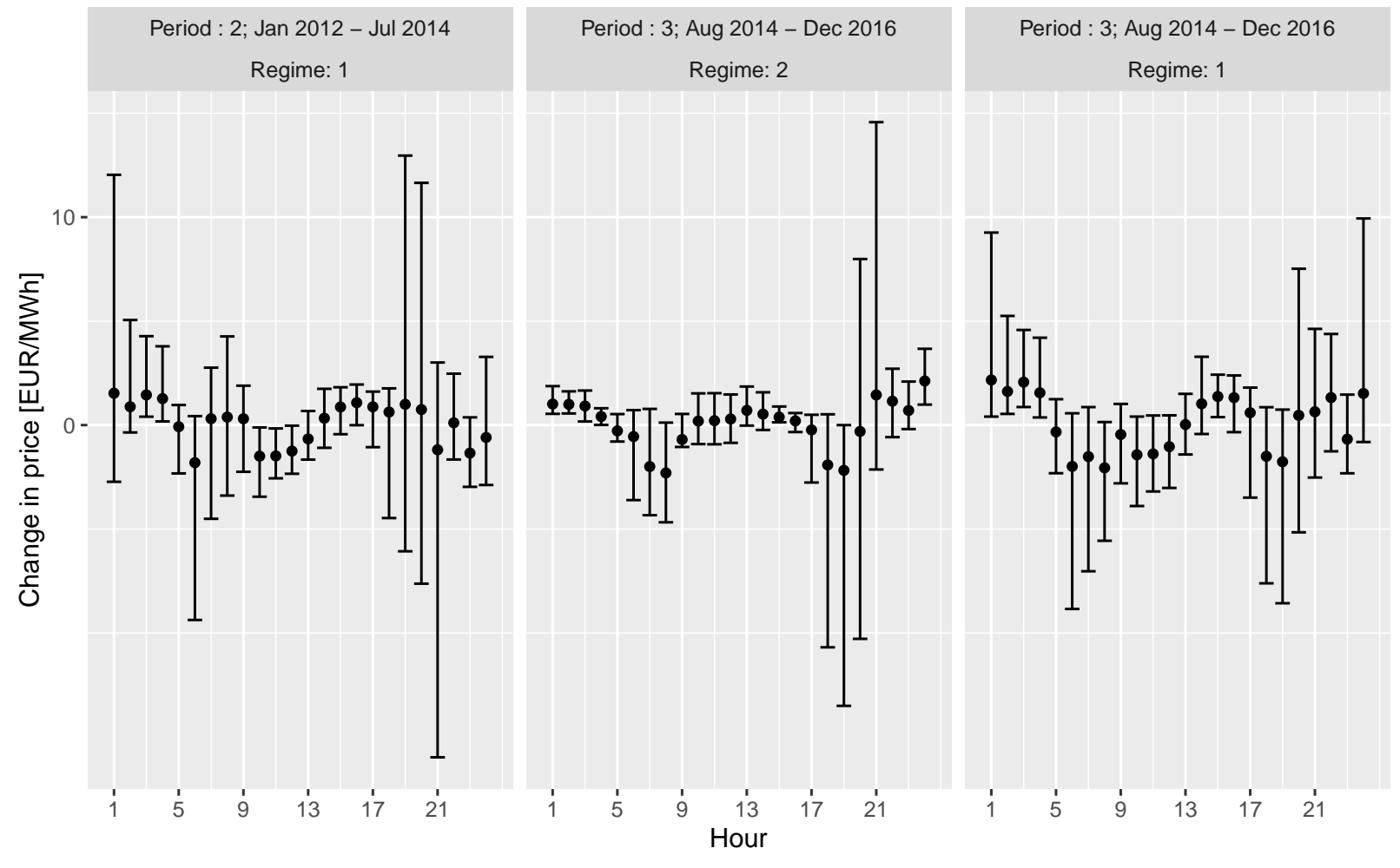


Figure A5: Robustness Check Electricity Market Coupling: Number of Hours with Avoided Negative Prices calculated by taking the Difference between the Counterfactual and the Actual Number of Hours with Negative Prices, by Hour of a Day and Period

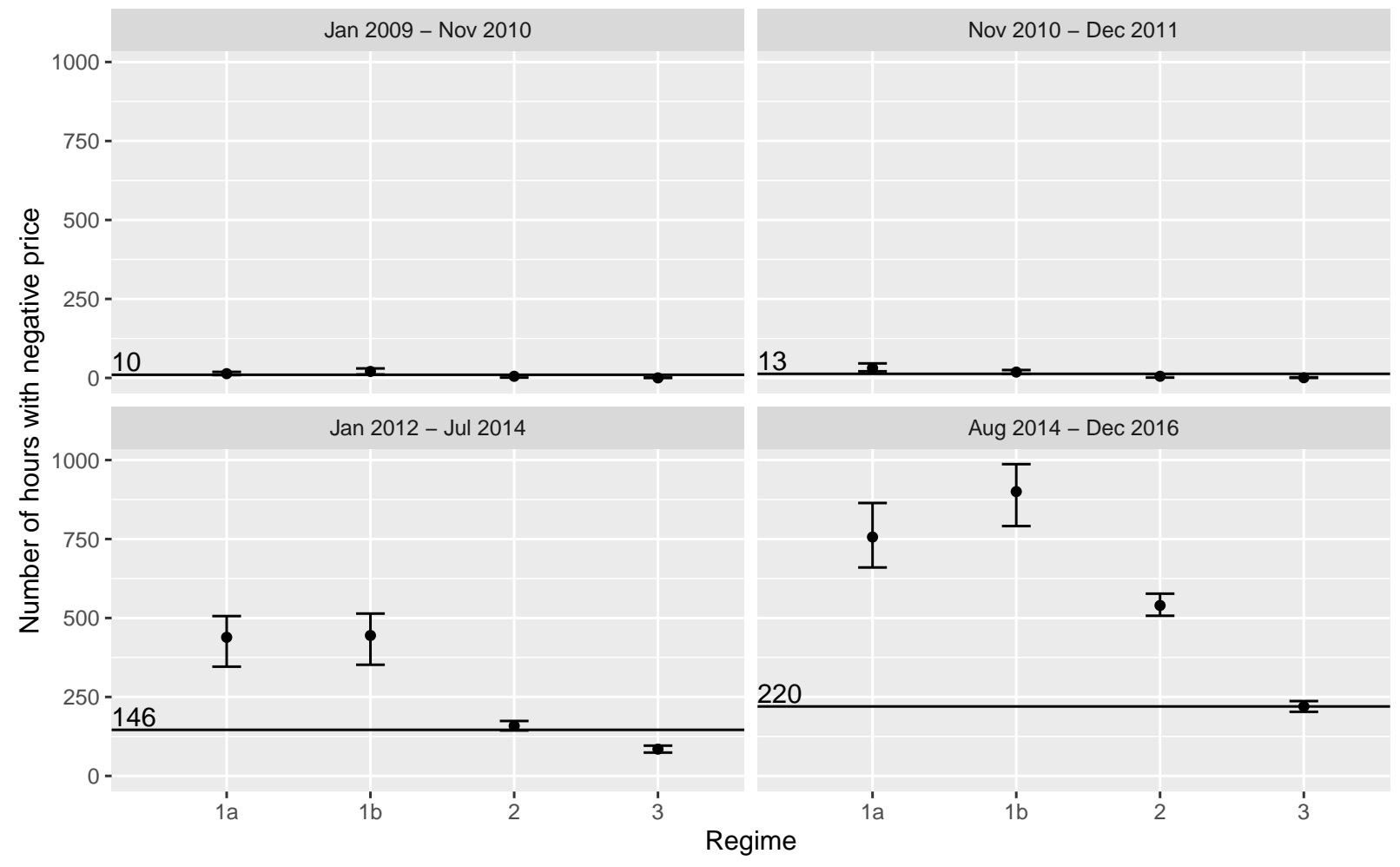


Figure A6: Robustness Check Electricity Market Coupling: Number of Hours with Prices below -20 Euros per Megawatthour calculated by taking the Difference between the Counterfactual and the Actual Number of Hours with Negative Prices, by Hour of a Day and Period

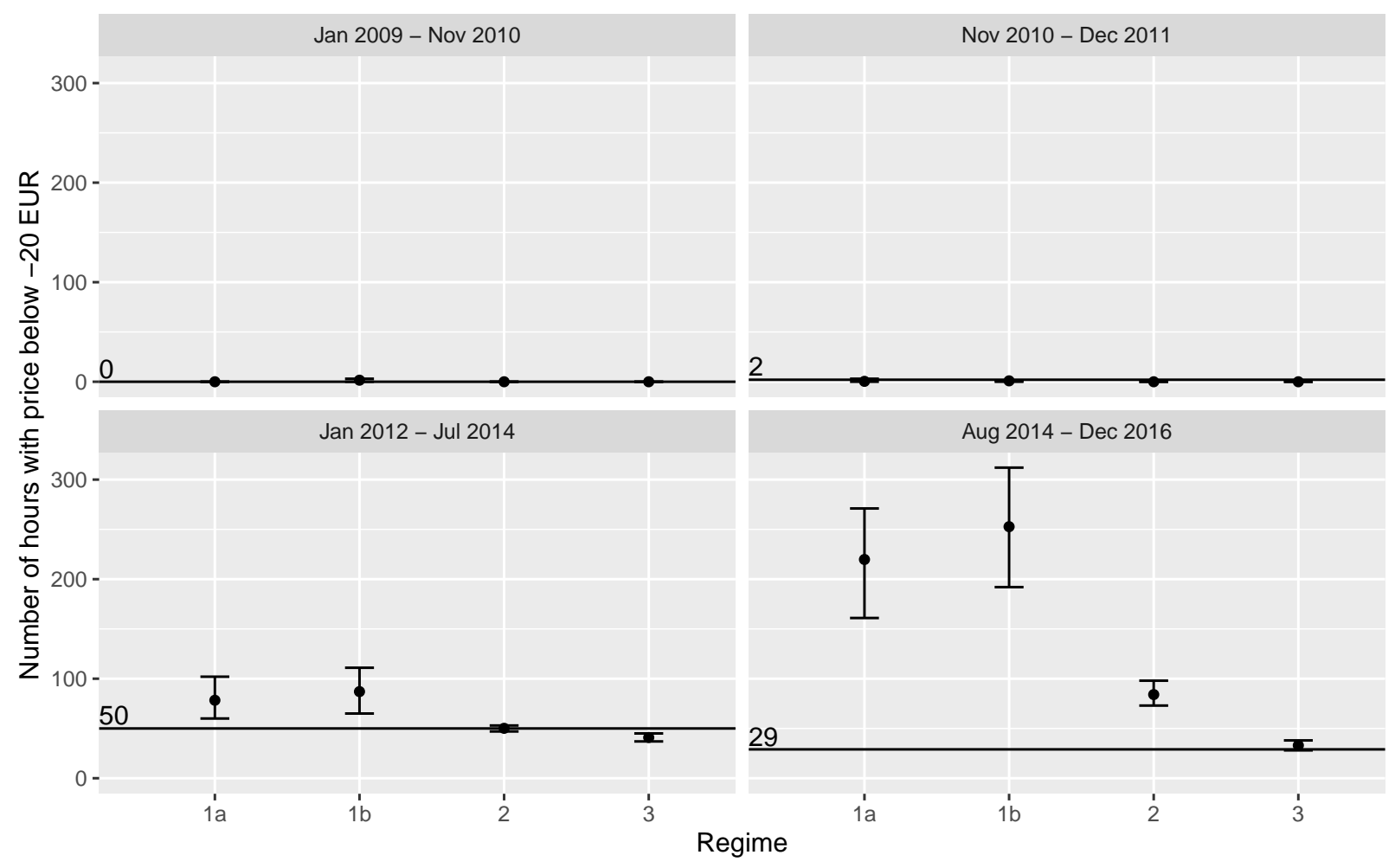




\section{References}

Agora (2019). European energy transition 2030: The big picture. Agora Energiewende, Berlin.

Andor, M., Flinkerbusch, K., Janssen, M., Liebau, B., and Wobben, M. (2010). Negative Strompreise und der Vorrang Erneuerbarer Energien. Zeitschrift für Energiewirtschaft, 34(2):91-99.

Andor, M., Frondel, M., and Vance, C. (2017). Germany's Energiewende: A tale of increasing costs and decreasing willingness-to-pay. The Energy Journal, 38(2):91-99.

Andor, M. and Voss, A. (2016). Optimal renewable-energy promotion: Capacity subsidies vs. generation subsidies. Resource and Energy Economics, 45:144-158.

Andor, M. A., Frondel, M., and Sommer, S. (2018). Equity and the willingness to pay for green electricity in Germany. Nature Energy, 3(10):876-881.

BMWi (2017). Erneuerbare Energien in Zahlen - Nationale und internationale Entwicklung im Jahr 2016. Bundesministerium für Wirtschaft und Energie, Berlin.

Breiman, L. (2001). Random forests. Machine Learning, 45(1):5-32.

Chipman, H. A., George, E. I., and McCulloch, R. E. (2010). BART: Bayesian additive regression trees. The Annals of Applied Statistics, 4(1):266-298.

Cludius, J., Hermann, H., Matthes, F. C., and Graichen, V. (2014). The merit order effect of wind and photovoltaic electricity generation in Germany 2008 - 2016: Estimation and distributional implications. Energy Economics, 44:302-313.

de Lagarde, C. M. and Lantz, F. (2018). How renewable production depresses electricity prices: Evidence from the German market. Energy Policy, 117:263-277. 
Fanone, E., Gamba, A., and Prokopczuk, M. (2013). The case of negative day-ahead electricity prices. Energy Economics, 35:22-34.

Fraunhofer (2018). Energy charts. https://energy-charts.de/. Fraunhofer Institute for Solar Energy Systems ISE, Freiburg.

Gerster, A. (2016). Negative price spikes at power markets: The role of energy policy. Journal of Regulatory Economics, 50(3):271-289.

Hill, J. L. (2011). Bayesian nonparametric modeling for causal inference. Journal of Computational and Graphical Statistics, 20(1):217-240.

IEA and IRENA (2018). IEA / IRENA joint policies and measures database. International Energy Agency and International Renewable Energy Agency, Paris and Masdar City.

Imbens, G. W. and Rubin, D. B. (2015). Causal inference in statistics, social, and biomedical sciences. Cambridge University Press, Cambridge.

Keppler, J. H., Phan, S., and Le Pen, Y. (2016). The impacts of variable renewable production and market coupling on the convergence of French and German electricity prices. The Energy Journal, 37(3):343-360.

Ketterer, J. C. (2014). The impact of wind power generation on the electricity price in Germany. Energy Economics, 44:270-280.

McCulloch, R., Sparapani, R., Gramacy, R., Spanbauer, C., and Pratola, M. (2018). BART: Bayesian Additive Regression Trees. R package version 2.1.

Nicolosi, M. (2010). Wind power integration and power system flexibility - An empirical analysis of extreme events in Germany under the new negative price regime. Energy Policy, 38(11):7257-7268.

Paschen, M. (2016). Dynamic analysis of the German day-ahead electricity spot market. Energy Economics, 59:118-128. 
Praktiknjo, A. and Erdmann, G. (2016). Renewable electricity and backup capacities: An (un-)resolvable problem? The Energy Journal, 37(SI2):89-106.

RES (2018). Legal sources on renewable energy. http://www.res-legal.eu. RES LEGAL Europe, Berlin.

Ringler, P., Keles, D., and Fichtner, W. (2017). How to benefit from a common European electricity market design. Energy Policy, 101:629-643.

Römer, B., Reichhart, P., Kranz, J., and Picot, A. (2012). The role of smart metering and decentralized electricity storage for smart grids: The importance of positive externalities. Energy Policy, 50:486-495.

TSO (2018). Informationen zur Direktvermarktung. https://www . netztransparenz.de/EEG/Monatliche-Direktvermarktung. German Tranmission System Operators, Bayreuth, Berlin, Dortmund, Stuttgart.

Weber, C. (2010). Adequate intraday market design to enable the integration of wind energy into the european power systems. Energy Policy, 38(7):3155-3163.

Würzburg, K., Labandeira, X., and Linares, P. (2013). Renewable generation and electricity prices: Taking stock and new evidence for Germany and Austria. Energy Economics, 40:159-171. 

